\title{
Welcoming Remarks from the Chair
}

Dear distinguished guests, our invited speakers, and participants of this conference

On behalf of the whole Program Committee, I would like to kindly welcome you to the $4^{\text {th }}$ International Conference on Bioinformatics, Biotechnology and Biomedical Engineering (BioMIC 2021). It is an honour to be here with you today. The BioMIC 2021 is part of the UGM Annual Scientific Conferences (UASC) series. This conference is presented by Badan Penerbit dan Publikasi, Universitas Gadjah Mada.

Our purpose is providing an ideal academic platform for researchers to disseminate their sophisticated research works and development of technologies and directions in bioinformatics, biotechnology, and biomedical engineering through five symposia: Bioinformatics and Biological Data Mining, Biomedical Science and Engineering, Biomolecular and Biotechnology, Drug Development and Nutraceutical, and Public Health symposium.

Today, we still have the grand challenges which are part of the big problem in global health, such as deadly diseases, the lack of access to medical care, and uncertainty adequate resources. As a scientist with greater encouragement, we could critically remove the obstacles to more rapid progress against the global health problem. We are also walking on the trajectory of the disruption era and connecting with the fourth industrial revolution. It has ensured the next phase of the healthcare ecosystem, to improve the great transformation and sustainable innovation. Therefore, the conference will take the theme "Artificial Intelligence, Big Data and Precision Healthcare: A Vision of the Future".

It is our satisfaction that we received 121 submissions throughout 13 countries from Indonesia, Malaysia, Vietnam, Philippines, Thailand, Japan, India, Saudi Arabia, Germany, Italy, UK, Netherlands, and USA. All submitted papers went through a rigorous review process.

This conference will not have become a reality without the support and assistance of many parties. On this occasion, I would like to sincerely thank the Rector of Universitas Gadjah Mada, BPP, DSSDI officers, all invited speakers and the organizing committee for arranging all needed facilities for the success of this conference. We also would like to thank reviewers for their valuable comments and suggestions.

Although we cannot greet each other in our usual way, we still have another way to interact, discuss, share insights, and enhance our mind with other researchers as well as colleagues from various perspectives. We do hope you find this event fruitful for your future career, for the sake of knowledge, and also for the benefit of humankind. Thank you.

Yogyakarta, October 6, 2021

Chair of the Organizing Committee, dr. Gunadi, Ph.D., Sp.BA. 


\title{
Welcoming Remarks from the Vice Rector for Research and Community Service of Universitas Gadjah Mada
}

\author{
Dear Distinguished Keynote Speakers, \\ Distinguished Invited Speakers and Participants, \\ Conference's Committee, \\ Ladies and Gentlemen.
}

On behalf of Universitas Gadjah Mada, it is my pleasure and privilege to welcome you all to the fourth International Conference on Bioinformatics, Biotechnology, and Biomedical Engineering (BioMIC 2021), hosted by Universitas Gadjah Mada (UGM). First of all, I would like to extend my gratitude to distinguished keynote speakers. Please allow me to express my sincere appreciation for Assoc.Prof. Takuji Yamada from Tokyo Institute of Technology, Japan; Prof. Joris Veltman from Newcastle University, United Kingdom; Dr. Daria Guseva from University of Hohenheim, Germany; and Prof. Dr. Ali Ghufron Mukti as President Director of BPJS Kesehatan Indonesia.

As a pioneering university, the history of UGM's education has opened the boundaries between academics and professionals across the world, to discover critically scientific inventions as the precious roots of knowledge for the benefit of humankind. This conference also has a role to answer the critical global health issues through the bioinformatics, biotechnology, and biomedical engineering views.

Today, we still have the grand challenges which are part of the big problem in global health, such as deadly diseases, the lack of access to medical care, and uncertainty adequate resources. As a scientist with greater encouragement, we could critically remove the obstacles to more rapid progress against the global health problem. We are also walking on the trajectory of the disruption era and connecting with the fourth industrial revolution. It has ensured the next phase of the healthcare ecosystem, to improve the great transformation and sustainable innovation. Therefore, the conference will take the theme "Artificial Intelligence, Big Data and Precision Healthcare: A Vision of the Future".

Besides the grand challenges, we are also in a pandemic situation, which requires us to adapt to the current situation. The pandemic has changed many habits of human life, but we believe that this situation cannot diminish our intellectual ability to always contribute knowledge to the world. Although BioMIC 2021 cannot be held physically, the integrity and quality of the research and content will remain and now be experienced in the virtual environment. It is bridging the gap among disciplines through this conference to bring and share their innovation, research, and ideas about our scientific issues today. UGM is proud to be leading the way in facilitating the interdisciplinary research dissemination of cutting-edge sharing information in diverse subjects. Let us think widely to identify research supports in the biomedical engineering field and bioinformatics to facilitate contact with biomolecular, drug development, and big data for public health. 
After 4 year, BioMIC 2021 as a part of the Annual Scientific Conference Series, holding annual gatherings for the brilliant ideas from Indonesia and overseas to share the latest findings in their fields. It proves UGM's consistency to preserve international academic relations. This series has been an enormous success to bring collaboration with our international partners, shaping the scientific networks, increasing Indonesia author's greatness in the global publication's scopes, and with a global readership, and underscoring UGM's place as a standard-bearer of scientific development.

We are honored and humbled to many experts who have attended this year's conference. We thank to the speakers for the expertise and knowledge that will bring to great discussion during. Special thanks are also extended to the organizing committee members in the BioMIC 2021 preparation, for their hard work, as well as the entire staff of UGM's Badan Penerbit dan Publikasi (BPP). And finally, I personally would like to thank all the conference participants who contribute to making this truly the most memorable BioMIC 2021. I wish you all to enjoy this conference, and above all a successful BioMIC 2021. Thanks for your very kind attention.

Vice Rector for Research and Community Service of Universitas Gadjah Mada, drg. Ika Dewi Ana, M.Kes., Ph.D. 